\title{
Buprenorphine and methadone were equally effective in reducing opiate or cocaine use
}

\author{
Schottenfeld RS, Pakes JR, Oliveto A, et al. Buprenorphine vs methadone maintenance treatment for concurrent opioid dependence \\ and cocaine abuse. Arch Gen Psychiatr 1997 Aug;54:713-20.
}

\section{Objective}

To determine whether buprenorphine is an effective alternative to methadone maintenance for patients with concurrent opioid and cocaine dependence.

\section{Design}

Randomised, double blind, controlled trial with 24 weeks of follow up.

\section{Setting}

New Haven, Connecticut, USA.

\section{Patients}

132 patients who were recruited to participate in a programme to treat opioid dependence. Inclusion criteria included a positive urine test for opioids; the Food and Drug Administration criteria for methadone maintenance; and the Diagnostic and Statistical Manual of Mental Disorders, 3rd edition, revised criteria for opioid and cocaine dependence. Exclusion criteria were dependence on alcohol or sedatives; risk of suicide or psychosis; inability to read or understand rating forms; or pregnancy. 116 patients $(88 \%$, mean age 33 $\mathrm{y}, 69 \%$ men) were included in the analysis.

\section{Intervention}

28 patients were allocated to high dose methadone, 65 $\mathrm{mg} /$ day; 29 to high dose buprenorphine, $12 \mathrm{mg} /$ day; 30 to low dose methadone, $20 \mathrm{mg} /$ day; and 29 to low dose buprenorphine, $4 \mathrm{mg} /$ day. Matching placebos were used. Patients had an hour of group counselling every week.

\section{Main outcome measures}

The main outcome measures were retention in treatment and the rate of urine samples that were positive for opioids and cocaine.

\section{Main results}

There were no differences in treatment retention among the high dose buprenorphine (55\%), low dose buprenorphine (35\%), high dose methadone (64\%), and low dose methadone
$(47 \%)$ groups $(\mathrm{p}=0.09)$. Patients treated with high dose buprenorphine or high dose methadone had lower rates of opioid positive tests than those treated with low dose methadone or low dose buprenorphine $(\mathrm{p}<0.02)$ (table). More patients treated with high dose methadone showed opioid abstinence for $\geqslant 3$ consecutive weeks than those treated with low dose methadone $(\mathrm{p}<0.005)$ and low dose buprenorphine $(\mathrm{p}<0.005)$ but not those treated with high dose buprenorphine $\{\mathrm{p}=0.14\} *$ (table). More patients treated with high dose buprenorphine showed opioid abstinence for $\geqslant 3$ weeks than those treated with low dose buprenorphine $(p<0.02)$ (table). No differences existed among groups for the rate of urine samples that tested positive for cocaine, nor for patients whose urine samples showed cocaine abstinence for $\geqslant 3$ weeks (table).

\section{Conclusions}

Higher doses of methadone or buprenorphine were more effective in reducing opioid use than lower doses of methadone or buprenorphine. The differences between higher doses of methadone and buprenorphine in the reduction of opioid use were not statistically significant.

*p values calculated from data in article.

Use of opioids and cocaine during maintenance treatment

\begin{tabular}{|c|c|c|c|c|}
\hline Outcome at 24 weeks & $\begin{array}{l}\text { Methadone } \\
65 \mathrm{mg}\end{array}$ & $\begin{array}{l}\text { Buprenorphine } \\
12 \mathrm{mg}\end{array}$ & $\begin{array}{l}\text { Methadone } \\
20 \mathrm{mg}\end{array}$ & $\begin{array}{l}\text { Buprenorphine } \\
4 \mathrm{mg}\end{array}$ \\
\hline \multirow{3}{*}{$\begin{array}{l}\text { Mean rate of opioid } \\
\text { positive tests } \\
\geqslant 3 \text { weeks opioid } \\
\text { abstinence } \\
\geqslant 3 \text { weeks cocaine } \\
\text { abstinence }\end{array}$} & $45 \%$ & $58 \%$ & $72 \%$ & $77 \%$ \\
\hline & $61 \%$ & $41 \%$ & $23 \%$ & $14 \%$ \\
\hline & $50 \%$ & $35 \%$ & $40 \%$ & $21 \%$ \\
\hline
\end{tabular}

Source of funding: National Institute on Drug Abuse.

For article reprint: Dr $R$ S Schottenfeld, 34 Park Street, Room S103, New Haven, CT 06519, USA. Fax +12037897088

\section{Commentary}

Buprenorphine is a partial agonist at the mu opiod receptor and an antagonist at the kappa opiod receptor, and is currently licensed in France and is awaiting approval from the Food and Drug Administration in the United States for use as a maintenance agent in opioid addicts. In clinical practice, the effects of buprenorphine are entirely accounted for by its partial mu agonism. It may precipitate withdrawal symptoms if it displaces a full mu agonist such as heroin or methadone from the mu receptor. It should therefore only be given to patients who are in mild withdrawal or if a time interval of 12 hours for heroin and 20 hours for methadone has elapsed, and even then doses $>4 \mathrm{mg}$ of buprenorphine need to be increased incrementally.
Its advantages over methadone are that it is much safer in overdose; it causes little subjective "high"; and withdrawal symptoms, even on abrupt termination, are relatively mild. Its long duration of activity means that it can be given daily, and on alternate days at high doses. Its primary disadvantage is that it can be easily snorted or injected, and this means that it should be given primarily by supervised consumption. The combination product with naloxone, when it becomes available, could help reduce its abuse potential.

This study is important for clinicians for a number of reasons: firstly, it involved patients who were opioid dependent and had concurrent cocaine abuse or dependence (a poor prognostic factor). Secondly, it clearly establishes that high dose treatment with buprenorphine or methadone is more effective than low dose treatment. Thirdly, it confirms that $4 \mathrm{mg}$ of buprenorphine is equivalent to $20 \mathrm{mg}$ of methadone. Fourthly, it shows that uncertainty still exists about dose equivalents at higher buprenorphine doses (a trend is reported favouring $60 \mathrm{mg}$ of methadone over $12 \mathrm{mg}$ of buprenorphine for reducing illicit opioid use). Finally, it suggests that the reduction of cocaine use reported in previous studies as occurring with buprenorphine is likely to be a nonspecific effect of treatment.

Professor David J Nutt, DM, MRCP, FRCPsych University of Bristol Bristol, UK 